\title{
INTEGRAÇÃO DE COMPUTADORES NAS PRÁTICAS PEDAGÓGICAS DE PROFESSORES DE MATEMÁTICA
}

\author{
E. C. SILVA'; J. A. FERNANDES ${ }^{2}$; B. D. SILVA ${ }^{3}$ e M. R. M. MORELATTI ${ }^{4}$ \\ ${ }^{1,4}$ Faculdade de Ciências e Tecnologia - Universidade Estadual Paulista (UNESP), ${ }^{2,3}$ Instituto de Educação - \\ Universidade do Minho \\ eliel_constantino@hotmail.com ${ }^{1}$
}

Submetido em 07/10/2016 - Aceito em 30/10/2016

DOI: $10.15628 /$ holos.2016.5165

\section{RESUMO}

Neste artigo apresentamos um recorte dos dados obtidos por meio da aplicação de um questionário a 44 professores de Matemática que estavam lecionando no ano letivo 2013/2014 na cidade de Braga (Portugal). Os dados produzidos integram uma investigação cujo objetivo foi verificar como o computador é utilizado nas aulas de matemática das escolas públicas de Braga. Caracterizamos os sujeitos da pesquisa e apresentamos suas perspectivas referentes à integração do computador nas escolas e em suas práticas pedagógicas. Os resultados mostram que a maioria dos professores
$(79,5 \%)$ utiliza o computador em todos os anos que lecionam. Mostram, também, que $72,7 \%$ dos professores de matemática participantes do estudo usam o computador para lecionar no Ensino Básico, enquanto que $36,4 \%$ o utilizam no Ensino Secundário e, em ambos os níveis de ensino, a Geometria é o tema onde o computador é mais utilizado no ensino de conteúdos matemáticos. Os resultados demonstram a satisfação desses professores com o uso de computadores em suas práticas de ensino, reconhecendo a relevância de tal utilização.

PALAVRAS-CHAVE: Computadores, Aulas de Matemática, Práticas pedagógicas de Professores de Matemática.

\section{NTEGRATION OF COMPUTERS IN THE TEACHING PRACTICES OF MATHEMATICS TEACHERS}

\begin{abstract}
In this paper we present an excerpt of the data obtained by applying a questionnaire to 44 Mathematics teachers who were teaching in the academic year 2013/2014 in Braga (Portugal). The data produced are part of an investigation aimed to see how the computer is used in math classes from public schools in Braga. We characterize the subjects and present their perspectives related to the integration of the computer in schools and their teaching practices. The results show that most teachers (79.5\%) use the computer every year to teach.
\end{abstract}

Also show that $72.7 \%$ of the study participants math teachers use the computer to teach in primary education, while $36.4 \%$ use it in secondary education and in both levels of education, the geometry is the subject where the computer is used more in the teaching of mathematical content. The results demonstrate the satisfaction of those teachers inusing computers in their teaching practices, recognizing the importance of such use.

KEYWORDS: Computers, Mathematics classes, Teaching practices of mathematics teachers. 


\section{INTRODUÇÃO}

Com o surgimento e evolução da tecnologia, recursos tecnológicos foram criados e inseridos na educação. O sistema educacional português sentiu essa inserção já na segunda metade dos anos oitenta, quando uma reforma educativa aconteceu em Portugal. Como consequência, as potencialidades do computador puderam ser reconhecidas e apoiadas no ensino de Matemática (COSTA; CANAVARRO, 2008). Esse apoio gerou projetos que tinham como objetivo, entre tantos outros, preparar e dar suporte aos professores na adaptação a essa tecnologia (VISEU, 2007).

A Associação de Professores de Matemática (APM) de Portugal publicou em 1988, o documento Renovação do currículo de matemática destacando as grandes potencialidades dos computadores no processo de aprendizagem de matemática, no qual o aluno passaria a desempenhar um papel mais ativo nesse processo. Essas potencialidades também foram destacadas pelo National Council of Teachers of Mathematics (NCTM, 1989, 2000) ao recomendar que fossem tiradas vantagens dos computadores em todos os níveis de ensino.

Ora, essas tendências e orientações, que valorizavam a utilização das novas tecnologias no ensino e na aprendizagem da matemática, discutidas nas mais variadas instâncias, rapidamente foram incorporadas nos programas escolares da disciplina de Matemática, observando-se um aprofundamento do seu uso com o decorrer do tempo (FERNANDES et al., 2006).

Essa utilização de computadores no ensino de Matemática permite que a ênfase normalmente dada à aprendizagem de técnicas, seja alterada "para o desenvolvimento de capacidades relacionadas com o raciocínio matemático" e contribui para o "desenvolvimento da capacidade de utilizar a Matemática na interpretação e intervenção no mundo que nos rodeia" (PONTE; CANAVARRO, 1997, p. 102).

[...] o computador deve ser utilizado como catalisador de uma mudança do paradigma educacional. Um novo paradigma que promove a aprendizagem ao invés do ensino, que coloca o controle do processo de aprendizagem nas mãos do aprendiz, e que auxilia o professor a entender que a educação não é somente a transferência de conhecimento, mas um processo de construção do conhecimento pelo aluno, como produto do seu próprio engajamento intelectual ou do aluno como um todo (VALENTE, 1993, p. 40).

Com efeito, este artigo apresenta dados pertencentes a uma investigação sobre o uso do computador nas aulas de matemática de escolas públicas da cidade de Braga, localizada na região Norte de Portugal. O objetivo da investigação foi verificar como o computador é utilizado nas aulas de matemática dessas escolas, seja pelos professores de matemática, seja pelos alunos, contribuindo para o processo de ensino e aprendizagem e como os laboratórios de informática dessas escolas são utilizados para o ensino da matemática.

Para isso, aplicamos um questionário aos professores de matemática dessas escolas a fim de obter suas percepções referentes a utilização do laboratório de informática para o processo de ensino da disciplina, a disponibilidade desses laboratórios para as aulas que não são relacionadas à 
informática, a disponibilidade de computadores nas escolas para serem utilizados nas aulas de matemática e a utilização dos computadores por professores e alunos.

A metodologia adotada foi ao encontro do objetivo de identificar os professores de matemática atuantes nessas escolas que trabalham com os recursos das TIC. Foram aplicados questionários aos professores e responsáveis pelos laboratórios, além de observação de uma aula em uma dessas escolas.

No que diz respeito aos resultados, foi possível fazer um mapeamento do uso do computador pelos professores de matemática dessas escolas, além dos conteúdos matemáticos mais trabalhados com esse recurso, os softwares mais utilizados, além de identificar as opiniões, vantagens e desvantagens sobre essa utilização nas aulas de matemática, segundo as concepções dos professores inquiridos e, ainda, foi possível identificar as limitações ainda existentes para a inserção do computador no ensino.

Os resultados ${ }^{4}$ que são apresentados nesse artigo são um recorte dos dados obtidos através da aplicação dos questionários a 44 professores de Matemática que estavam lecionando em escolas públicas (Ensino Básico/Ensino Fundamental e Ensino Secundário/Ensino Médio) ${ }^{5}$ da cidade de Braga (no ano letivo 2013/2014) referentes ao uso que eles faziam do computador em suas práticas pedagógicas. Apresenta-se, ainda, a perspectiva desses professores referente à inserção desse recurso tecnológico nas escolas e nas aulas de Matemática.

\title{
2 O COMPUTADOR E OS PROGRAMAS DE MATEMÁTICA DE PORTUGAL
}

Nos programas de Matemática do Ensino Básico e do Ensino Secundário em vigor, quando este estudo foi realizado, recomendava-se a utilização do computador em sala de aula e o uso de laboratórios. No programa de Matemática do Ensino Básico preconiza-se que

\begin{abstract}
ao longo de todos os ciclos, os alunos devem usar calculadoras e computadores na realização de cálculos complexos, na representação de informação e na representação de objetos geométricos. O seu uso é particularmente importante na resolução de problemas e na exploração de situações, casos em que os cálculos e os procedimentos de rotina não constituem objetivo prioritário de aprendizagem, e a atenção se deve centrar nas condições da situação, nas estratégias de resolução e na interpretação e avaliação dos resultados. A calculadora e o computador não devem ser usados para a realização de cálculos imediatos ou em substituição de cálculo mental (Ministério da Educação, 2007, p. 9).
\end{abstract}

E ainda,

deve tirar-se partido das possibilidades de experimentação que os computadores oferecem nos domínios geométrico e numérico, e no tratamento de dados. A utilização

\footnotetext{
${ }^{4}$ Esses resultados foram parcialmente apresentados na $12^{\text {th }}$ International Conference on Technology in Mathematics Teaching realizada na Universidade do Algarve, em Faro (Portugal), em 24-27 de junho de 2015.

${ }^{5}$ Usamos correspondência do sistema de ensino português ao sistema brasileiro, em que o ensino básico em Portugal corresponde ao ensino fundamental no Brasil e o ensino secundário ao ensino médio.
} 
adequada de recursos tecnológicos como apoio à resolução de problemas e à realização de atividades de investigação permite que os alunos se concentrem nos aspectos estratégicos do pensamento matemático (Ministério da Educação, 2007, p. 62).

Quanto aos Programas de Matemática do Ensino Secundário, nomeadamente, ao nível do 10 o ano, tanto para a Matemática A como para a Matemática $\mathrm{B}^{6}$, o computador é citado como recurso a ser utilizado na didática prevista para a Matemática (Ministério da Educação, 2001a, 2001b). E pode ler-se ainda que

os recursos escolhidos deverão ter em vista tanto a sua utilização na própria sala do Laboratório de Matemática, como uma utilização de recursos adequados em salas de aulas indiferenciadas. É considerado indispensável o uso de:

- calculadoras gráficas (para trabalho regular na sala de aula ou para demonstrações com todos os estudantes, usando uma calculadora com "view-screen");

- uma sala de computadores com "software" adequado para trabalho tão regular quanto possível;

- um computador ligado a um "Datashow" ou projetor de vídeo (para demonstrações) (Ministério da Educação, 2001a, 2001b, p. 14).

Referente à tecnologia, o mesmo programa cita que:

Não é possível atingir os objetivos gerais e competências deste programa sem recorrer à dimensão gráfica, e essa dimensão só é plenamente atingida quando os estudantes traçam uma grande quantidade e variedade de gráficos com apoio de tecnologia adequada (calculadoras gráficas e computadores) (Ministério da Educação, 2001a, 2001b, p. 15).

Quanto ao uso de computadores, nos dois Programas (2001a, 2001b) é referido que:

O computador, pelas suas potencialidades, nomeadamente nos domínios da Geometria Dinâmica, da representação gráfica de funções e da simulação, permite atividades não só de exploração e pesquisa como de recuperação e desenvolvimento, pelo que constitui um valioso apoio a estudantes e professores, devendo a sua utilização considerar-se obrigatória neste programa. Vários tipos de programas de computador são muito úteis e enquadram-se no espírito do programa. Os programas de Geometria Dinâmica, de Cálculo Numérico e Estatístico, de Gráficos e Simulações e de Álgebra Computacional fornecem diferentes tipos de perspectivas tanto a professores como a estudantes. O número de programas disponíveis no mercado português aumenta constantemente.Neste sentido recomenda-se enfaticamente o uso de computadores, tanto em salas onde os estudantes poderão ir realizar trabalhos práticos, como em salas com condições para se dar uma aula em ambiente computacional (nomeadamente nos Laboratórios de Matemática), além do partido que o professor pode tirar como ferramenta de demonstração na sala de aula usando um Datashow com retroprojetor ou projetor de vídeo. Os estudantes devem ter oportunidade de trabalhar diretamente com um computador, com a frequência possível

${ }^{6}$ O programa de Matemática A diz respeito aos Cursos Científico-Humanísticos de Ciências e Tecnologias e de Ciências Socioeconómicas e o programa de Matemática B diz respeito aos Cursos Profissionais. 
de acordo com o material disponível. Nesse sentido, as escolas são incentivadas a equiparse com o material necessário para que tal tipo de trabalhos se possa realizar com a regularidade que o professor julgar aconselhável (Ministério da Educação, 2001a, 2001b, p.16)

Ainda sobre o Programa de Matemática de Portugal, ao nível do 10 을 ano, tanto para a Matemática A como para a Matemática B, é defendido o uso da tecnologia como indicação metodológica e cita-se sua importância para a aprendizagem do aluno no desenvolvimento do tema transversal Tecnologia e Matemática.Em relação aos temas, o computador é citado nos dois Programas para o desenvolvimento dos temas Funções e Gráficos e Estatística.

Quando observamos o Prograna de Matemática do Ensino Secundário, nomeadamente no nível do 11 o ano, não encontramos nenhuma referência ao computador no Programa de Matemática A (2002a), ao contrário da calculadora gráfica que é mencionada em todos os temas. No Programa de Matemática B (2002b), o computador é mencionado como indicação metodológica no desenvolvimento dos temas Movimentos não Linear, Taxas de Variação e Funções Racionais, com a justificação de facilitar a visualização e permitir que o aluno veja inúmeros exemplos.

Referente ao Programa de Matemática do Ensino Secundário do 12ำ ano,de Matemática A (2002c), o computador é citado no tema Trigonometria e Números Complexos no "estudo intuitivo com base no círculo trigonométrico, tanto a partir de um gráfico particular, como usando calculadora gráfica ou computador" (p. 07) no desenvolvimento de Funções seno, cosseno e tangente. Para a Matemática B (2002d), o computador surge nos temas:

- Modelos de Probabilidade como recurso metodológico para resolução de problemas simples envolvendo distribuições de probabilidade, determinação da média e desviopadrão de uma distribuição;

- Modelos contínuos não lineares, exponencial, logarítmico e logístico como um recurso facilitador na compreensão do tema e prolongamento do estudo sobre progressões geométricas;

Finalmente, no Programa de Matemática Aplicada às Ciências Sociais (2001c) salientaseque

Os estudantes devem ter oportunidade de trabalhar diretamente com um computador, com a frequência possível de acordo com o material disponível. O trabalho com computadores deveria ainda ser explorado e desenvolvido na Área de Projeto e em atividades complementares, não podendo, contudo, o trabalho com computadores ser remetido exclusivamente para fora do trabalho regular da aula de Matemática (ME, 2001c, p. 10).

Em síntese, o computador é tido como uma indicação metodológica e um recurso facilitador da aprendizagem, compreensão e visualização por parte do aluno, possibilitando, também, mais recursos para os processos de ensino e aprendizagem. 


\section{METODOLOGIA}

Levando em conta o objetivo principal do estudo, optou-se por uma abordagem qualitativa, pois "consiste em descrições detalhadas de situações com o objetivo de compreender os indivíduos em seus próprios termos" (Goldenberg, 2013, p.53), permitindo ao pesquisador compreender como os sujeitos pensam e agem em um determinado contexto. Essa escolha pela abordagem qualitativa está relacionada com a temática da pesquisa e com a questão que a norteia, por ser uma questão de natureza aberta que requer uma atitude compreensiva do pesquisador. Com o objetivo de realizar um mapeamento sobre o uso do computador pelos professores de matemática que lecionam na cidade de Braga e coletar informações que descrevam as opiniões desses professores referentes ao uso do computador no ensino da matemática e os conteúdos mais trabalhados por eles com esse recurso tecnológico, foi adotado uma investigação de tipo survey por questionário, baseado em Hill e Hill (2002), e observação de aula (gravações de vídeo) e entrevistas. Os dados que são apresentados e discutidos nesse artigo são referentes a uma parte dos dados produzidos através do questionário.

O questionário foi aplicado aos professores de matemática que estavam lecionando no ano letivo 2013/2014 na cidade de Braga. Ele é anônimo, tendo essa informação contida na mensagem de apresentação do questionário de forma a assegurar aos professores respondentes o anonimato das respostas. Ele foi formulado de forma a obter informações que possibilitassem perceber possíveis fatores que influenciam o professor na escolha em utilizar ou não o computador em suas aulas. O questionário contém perguntas sobre características dos professores que podem influenciá-los nessa escolha, tais como, idade, sexo, número de anos de serviço docente e nível ou níveis de ensino em que leciona atualmente e em que já lecionou. Além disso, as perguntas foram baseadas em percepções obtidas em uma investigação (inicial) sobre o uso dos laboratórios de informática na cidade de Presidente Prudente, Brasil, e em trabalhos como Blanco e Silva (1993), Costa e Canavarro (2008), Viseu (2007), Fernandes e Vaz (1998), Fernandes (1998), Viseu, Lima e Fernandes (2013), Lima (2012) e Ministério da Educação (2008), que abordam o uso da tecnologia no ensino em Portugal, relatam a influência dessa utilização na aprendizagem da matemática por alunos portugueses e afirmam a importância de utilizá-la no ensino de matemática, incluindo a forte influência da calculadora gráfica.

Portanto, com base nesses estudos, fez-se uma verificação da adequação das perguntas frente ao objetivo proposto, inserindo-se no questionário perguntas de modo a poder captar e entender a visão dos professores sobre o computador, suas vantagens e desvantagens e também o motivo pelo qual o utilizam nas aulas para que fosse possível mapear de forma mais segura as outras informações coletadas.

Na totalidade, 44 professores de matemática responderam ao questionário proposto que Ihes foi entregue pessoalmente pelo primeiro autor deste artigo e em alguns casos via e-mail e devolvido por um intermediário. Os questionários puderam ser respondidos de acordo com o tempo dos professores, sem a presença do autor ou intermediários. Contudo, um grupo pequeno de professores (14) respondeu ao questionário com o autor presente a pedido deles e também tendo em conta a logística do tempo e locomoção do primeiro autor deste artigo até a escola. 
Alguns dos questionários foram entregues em envelopes para o coordenador do departamento de Ciências e Matemática das Escolas e da mesma forma, devolvidos ao autor, sempre garantindo o anonimato.

$\mathrm{Na}$ Tabela 1 apresenta-se a caracterização dos professores de Matemática que responderam ao questionário, segundo as variáveis: idade, sexo, número de anos de serviço docente, nível ou níveis de ensino em que tinha lecionado e nível de escolaridade que lecionava na época da investigação.

Tabela 1: Caracterização dos professores de matemática

\begin{tabular}{lc}
\hline Variáveis & Frequência (\%) \\
\hline Idade & \\
Até 40 anos & $7(15,9)$ \\
Entre 40 anos e 60 anos & $35(79,55)$ \\
Mais de 60 anos & $2(4,55)$ \\
Sexo & \\
$\quad$ Feminino & $37(84,1)$ \\
$\quad$ Masculino & $7(15,9)$ \\
Número de anos de serviço docente & \\
Até 20 anos & $11(25,0)$ \\
$\quad$ Entre 20 anos e 30 anos & $19(43,18)$ \\
$\quad$ Mais de 30 anos & $9(20,45)$ \\
Sem informação & $5(11,4)$ \\
Nível ou níveis de ensino em que lecionou & \\
$\quad$ Ensino Básico & $28(63,64)$ \\
$\quad$ Ensino Secundário & $16(36,36)$ \\
Nível de escolaridade que leciona atualmente & \\
$\quad$ Ensino Básico & $28(63,64)$ \\
Ensino Secundário & $16(36,36)$ \\
\hline
\end{tabular}

Para além das variáveis independentes já referidas (ver Tabela 1), o questionário incluía 12 itens de escolha múltipla centrados no tema "O uso de computadores no ensino da matemática", sendo itens de concordância; cinco itens resposta objetiva, como uma ou mais opções de resposta e sendo dois deles com justificativas; e seis itens de opinião pessoal (dissertativas). A escala de concordância era formada por 4 pontos: discordo totalmente, discordo, concordo e concordo totalmente.

Em termos de análise de dados, utilizou-se o software de análise estatística Statistical Package for the Social Sciences (SPSS), versão 22 para Windows, e recorreu-se a métodos de estatística descritiva, essencialmente a determinação de frequências, médias e desvios padrão, com os resultados eventualmente resumidos em tabelas.

\section{RESULTADOS E DISCUSSÕES}

Referente ao uso do computador em suas práticas pedagógicas, os professores participantes do estudo avaliaram alguns aspectos através de uma escala de concordância, tendo 
por pontos: DT - Discordo Totalmente, D - Discordo, C - Concordo, CT - Concordo Totalmente. Recorrendo a porcentagens e determinando os valores da média e do desvio-padrão, neste último caso depois de codificados os valores da escala (DT - 1, D - 2, C - 3 e CT - 4) e agrupados os valores DT/D e C/CT, obtiveram-se os resultados que constam na Tabela 2.

Tabela 2: Aspectos relativos ao uso do computador em sala de aula

\begin{tabular}{|c|c|c|c|c|c|}
\hline \multirow[b]{2}{*}{ Item } & \multicolumn{3}{|c|}{$\%$ de respostas } & \multirow{2}{*}{$\bar{x}$} & \multirow{2}{*}{$S$} \\
\hline & DT/D & $\mathrm{C} / \mathrm{CT}$ & $N R$ & & \\
\hline $\begin{array}{l}\text { Tive computadores disponíveis sempre que os pretendi } \\
\text { utilizar nas minhas aulas }\end{array}$ & 36,4 & 50,0 & 13,6 & 2,7 & 0,97 \\
\hline $\begin{array}{l}\text { Tenho conhecimento suficiente sobre o computador } \\
\text { para o poder usar nas minhas aulas }\end{array}$ & 2,3 & 84,1 & 13,6 & 3,2 & 0,47 \\
\hline $\begin{array}{l}\text { Tenho conhecimento suficiente sobre como usar o } \\
\text { computador para ensinar matemática. }\end{array}$ & 18,2 & 68,2 & 13,6 & 3,0 & 0,70 \\
\hline $\begin{array}{l}\text { Estou satisfeito/a com a forma como tenho usado o } \\
\text { computador nas minhas aulas }\end{array}$ & 9,1 & 77,3 & 13,6 & 3,1 & 0,54 \\
\hline $\begin{array}{l}\text { O uso do computador tem-me permitido explorar com } \\
\text { os meus alunos uma matemática mais realista }\end{array}$ & 13,6 & 72,7 & 13,6 & 3,1 & 0,61 \\
\hline $\begin{array}{l}\text { O uso do computador nas minhas aulas tem-me } \\
\text { permitido centrar menos o ensino nos aspectos de } \\
\text { cálculo. }\end{array}$ & 56,8 & 29,5 & 13,6 & 2,3 & 0,78 \\
\hline $\begin{array}{l}\text { O uso do computador tem-me permitido centrar mais o } \\
\text { ensino nas questões de interpretação e significado. }\end{array}$ & 22,7 & 61,4 & 15,9 & 2,7 & 0,63 \\
\hline $\begin{array}{l}\text { Estou satisfeito/a com a forma como os meus alunos } \\
\text { têm usado o computador nas minhas aulas. }\end{array}$ & 36,3 & 45,4 & 18,2 & 2,6 & 0,70 \\
\hline $\begin{array}{l}\text { Os meus alunos preferem aprender matemática usando } \\
\text { o computador do que usando apenas outros meios }\end{array}$ & 27,3 & 54,6 & 18,2 & 2,8 & 0,69 \\
\hline $\begin{array}{l}\text { Os meus alunos envolvem-se mais na aprendizagem } \\
\text { quando usam o computador. }\end{array}$ & 31,8 & 52,3 & 15,9 & 2,8 & 0,68 \\
\hline $\begin{array}{l}\text { Os meus alunos trabalham mais em grupo quando usam } \\
\text { o computador. }\end{array}$ & 52,3 & 29,6 & 18,2 & 2,4 & 0,60 \\
\hline
\end{tabular}

Nota: DT/D - Discordo Totalmente ou Discordo; C/CT - Concordo ou Concordo Totalmente; NR - Não Responde.

Analisando os dados que estão contidos na Tabela 2, verifica-se que metade (50\%) dos professores tiveram computadores disponíveis sempre que os pretenderam utilizar em suas aulas. Também se verifica nesse aspecto uma maior variabilidade de respostas por parte dos professores. A maioria dos professores $(84,1 \%)$ tem conhecimento suficiente sobre o computador para o poder usar em suas aulas, enquanto uma minoria (2,3\%) discorda ou discorda totalmente 
dessa afirmação. É neste item que se observa uma menor variabilidade das respostas dos professores de matemática que lecionam na cidade de Braga.

Em relação a ter conhecimento suficiente sobre como usar o computador para ensinar matemática, $68,2 \%$ dos professores concorda ou concordam totalmente, enquanto que poucos (18,2\%) discordam ou discordam totalmente. A Tabela 2 também retrata a satisfação dos professores com a forma como têm usado o computador em suas aulas. Com uma média de 3,1 e desvio padrão de 0,54 , a maioria dos professores $(77,3 \%)$ estão satisfeitos, enquanto que a minoria $(9,1 \%)$ não está. Uma porcentagem de $45,4 \%$ está satisfeita com a forma como os seus alunos têm usado o computador em suas aulas, enquanto que uma porcentagem um pouco menor (36,3\%) não está. Quanto ao uso do computador em sala de aula, a maioria dos professores $(72,7 \%)$ concorda ou concorda totalmente que o computador tem-lhes permitido explorar com os seus alunos uma matemática mais realista, enquanto poucos professores $(13,6 \%)$ discordam ou discordam totalmente. Ainda, apenas uma pequena porcentagem de professores (29,5\%) concorda ou concorda totalmente que o computador tem permitido centrar menos o ensino nos aspetos de cálculo, enquanto que a maioria $(56,8 \%)$ discorda ou discorda totalmente que o computador permite centrar menos o ensino nos aspectos de cálculo. Complementando as informações referentes ao uso do computador nas aulas, a maioria $(61,4 \%)$ concorda e concorda totalmente que o computador tem permitido centrar mais o ensino nas questões de interpretação e significado, contrariando $22,7 \%$ dos professores que discordam ou discordam totalmente. Analisando a média deste último aspecto citado, concluiu-se que os professores concordam $(2,7)$ que o uso do computador tem-lhes permitido centrar mais o ensino nas questões de interpretação e significado.

Os três últimos aspectos incluídos na tabela referem-se à análise feita dos alunos pelos professores no tocante ao uso do computador e a aprendizagem dos alunos e à forma de trabalhar dos alunos. Nos aspectos: "os meus alunos preferem aprender matemática usando o computador do que usando apenas outros meios" e "os meus alunos envolvem-se mais na aprendizagem quando usam o computador", a maioria dos professores (54,6\% e 52,3\%, respectivamente) concorda ou concorda totalmente que seus alunos preferem e envolvem-se mais na aprendizagem quando usam o computador; já no caso de que seus alunos trabalhem mais em grupo quando usam o computador, a maioria $(52,3 \%)$ discorda ou discorda totalmente.

Face ao maior valor possível da média $(4,0)$, verifica-se que os professores de matemática de Braga que participaram no estudo manifestaram um nível alto de concordância sobre terem conhecimento suficiente sobre o computador para o poder usar em suas aulas e como usá-lo para ensinar matemática. Também concordam que o computador tem-lhes permitido explorar uma matemática mais realista com seus alunos e estão satisfeitos com a forma com que têm usado o computador em suas aulas. Em contraponto, não concordam que o uso do computador tem permitido centrar menos o ensino nos aspectos de cálculo e nem que os alunos trabalham mais em grupo quando usam o computador. Em um nível de concordância mediano, os professores concordam que tiveram computadores disponíveis sempre que os pretenderam utilizar e que estão satisfeitos com a forma como os seus alunos têm usado o computador nas aulas. 
Perspectivam, embora muito pouco, que o computador tem permitido centrar mais o ensino nas questões de interpretação e significado.

Os dados produzidos pelo questionário revelaram, ainda, que a maioria $(84,1 \%)$ dos professores de Matemática participantes do estudo utiliza o computador em suas práticas pedagógicas para ensinar matemática, enquanto alguns $(15,9 \%)$ não o utilizam. Ainda, os que não utilizam o computador em suas práticas pedagógicas também nunca utilizaram o computador para o ensino da disciplina, ou seja, deduzimos que os professores representados pelos $15,9 \%$ nunca experimentaram integrar o computador em suas práticas pedagógicas.

Concernente aos professores que utilizam o computador atualmente em suas aulas $(84,1 \%)$, a grande maioria $(43,2 \%)$ utiliza-o semanalmente, em média 2,3 vezes por semana, um pouco menos $(22,7 \%)$ utiliza-o em todas as aulas, $15,9 \%$ utilizam-no mensalmente, em média 3,9 vezes por mês e poucos $(2,3 \%)$ utilizam-no uma ou duas vezes por período escolar. Ainda, uma quantidade pouco expressiva de professores $(15,9 \%)$ que utilizam o computador atualmente em suas aulas não respondeu sobre a frequência com que utilizam o computador em suas aulas.

Referente aos anos escolares em que utilizam o computador, a maioria dos professores $(79,5 \%)$ utiliza em todos os anos que lecionam, enquanto poucos professores $(9,1 \%)$ não o utilizam em todos os anos que lecionam.

A maior parte da amostra dos professores inquiridos $(72,73 \%)$ usa o computador para lecionar no Ensino Básico, enquanto outra parte menor dos professores (36,36\%) o utiliza no Ensino Secundário. Este último resultado pode ser entendido como uma consequência do uso da calculadora gráfica tão presente no Ensino Secundário em Portugal. Há professores que utilizam em ambos os níveis de ensino paralelamente.

No Ensino Básico, a grande maioria dos professores $(68,2 \%)$ utiliza o computador no tema Geometria e Medida, seguido pelo tema Organização e Tratamento de Dados (59,1\%), Álgebra $(36,4 \%)$, Números e Operações $(31,8 \%)$ e, por fim, uma quantidade mínima (2,3\%) utiliza-o no tema História da Matemática.

No Ensino Secundário, a maioria dos professores (27,3\%) utiliza o computador para o ensino do tema Geometria no Plano e no Espaço, 25\% dos professores utilizam-no em Estatística, 22,7\% dos professores utilizam-no em Funções e Gráficos e 18,4\% dos professores utilizam-no para ensinar Trigonometria. Uma pequena quantidade de professores $(9,1 \%)$ utiliza-o em Sucessões Reais, 6,8\% em Probabilidades, 4,5\% em Cálculo Diferencial e, ainda, uma quantidade mínima de professores (2,3\%) utiliza-o em Números Complexos. Em ambos os níveis de ensino, a Geometria é o tema onde o computador é mais utilizado no ensino de conteúdos matemáticos.

No ensino-aprendizagem desses temas matemáticos os professores têm recorrido a alguns softwares que possibilitam e/ou facilitam a compreensão do aluno, a visualização e a abstração. No total são 21 softwares que estão listados na Figura 1, podendo observar-se também as porcentagens de professores que utilizam cada um desses softwares. 


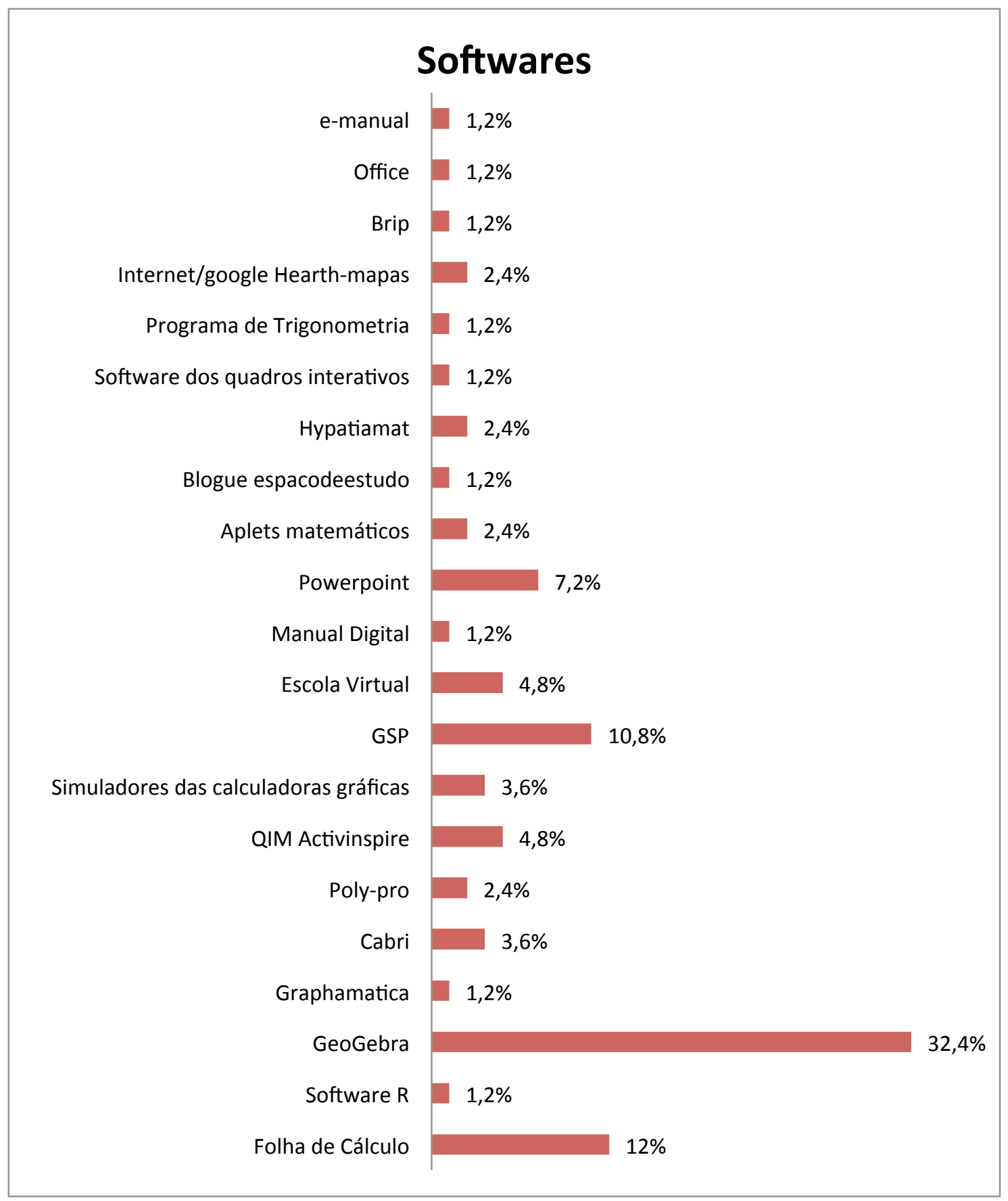

Figura 1: Softwares utilizados pelos professores

Face aos maiores valores de porcentagens, verifica-se que os professores de matemática inquiridos utilizam mais o software GeoGebra em suas aulas (32,4\%), seguido da Folha de Cálculo (12\%), do GSP $(10,8 \%)$ e do PowerPoint (7,2\%). A plataforma Escola Virtual, que não é propriamente um software, também é referida por alguns professores (4,8\%) e os restantes softwares são usados por um número reduzido de professores $(1,2 \%-4,8 \%)$.

Para além dos softwares, alguns professores têm usado também algumas plataformas digitais no ensino da matemática. Considerando-se como plataforma digital sites, redes sociais, blogs, etc., verifica-se que a maioria dos professores inquiridos $(65,9 \%)$ utiliza plataformas digitais e poucos $(18,2 \%)$ não as utilizam (Figura 4). Dentre as plataformas digitais utilizadas, destaca-se a 
Escola Virtual, da Porto Editora (26,4\%). Verificam-se ainda a utilização de redes sociais (7,2\%) e blogs matemáticos $(16,8 \%)$, estes últimos com origem em iniciativas das próprias escolas. Estes resultados confirmam a aceitação do computador pelos professores e o reconhecimento da sua utilidade e contribuição para o processo de ensino e aprendizagem em matemática.

Figura 2: Plataformas digitais utilizadas pelos professores

$$
\begin{array}{r}
\text { Wikipédia } \\
\text { GeoGebra Virtual } \\
\text { e-mail }
\end{array}
$$

Jogos Matemáticos

Associação de Professores de Matemática

Portalmath

Gave - Gabinete de Avaliação Educacional

Hypatiamat

Sites espanhóis

Sites brasileiros

Khan Academy

Blogues matemáticos

Moodle

Escola Virtual da Porto Editora

Rede social

Web 2.0
$2,4 \%$

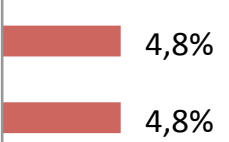

$2,4 \%$

$2,4 \%$

$4,8 \%$

$4,8 \%$

$9,6 \%$

$2,4 \%$

$2,4 \%$

$2,4 \%$ 


\section{CONCLUSÃO}

O computador está integrado nas aulas de Matemática das escolas públicas da cidade de Braga. Mesmo sem terem o suporte necessário, os professores utilizam esse recurso informático em suas aulas e confirmam suas potencialidades, pois as elevadas porcentagens revelam um considerável nível de aceitação do uso do computador no ensino pelos professores de matemática e a satisfação com a utilização do computador em suas aulas. Ao todo, entre os professores participantes do estudo, são utilizados 21 softwares educacionais e 16 plataformas digitais.

Constatamos também que os professores que não utilizam o computador atualmente nas aulas para ensinar matemática, num total de 15,9\%, nunca experimentaram integrar o computador em suas aulas. A maior parte dos professores do Ensino Básico refere usar o computador em suas aulas, enquanto todos os do Ensino Secundário o utilizam. Em ambos os níveis de ensino, a Geometria é o tema em que onde o computador é mais utilizado no ensino de conteúdos matemáticos.

Em termos de perspectivas dos professores acerca do uso do computador no ensino e aprendizagem da matemática, eles consideram possuir conhecimentos suficientes sobre o computador e de como utilizá-lo em suas aulas para ensinar matemática. Também assumem que o computador permite-lhes explorar uma matemática contextualizada com seus alunos e estão satisfeitos com a forma como têm usado o computador em suas aulas. Em geral, os professores tiveram computadores disponíveis sempre que os pretenderam utilizar, estão satisfeitos com a forma como os seus alunos têm usado o computador nas aulas e o computador tem-lhes permitido centrar maiso ensino nas questões de interpretação e significado, envolver mais os alunos na aprendizagem e ir ao encontro às suas preferências. Finalmente, o uso do computador não tem permitido centrar menos o ensino nos aspetos de cálculo e que os alunos trabalhem mais em grupo quando usam o computador.

Como relatado no artigo, o computador faz parte das indicações metodológicas dos Programas escolares e é visto como um recurso facilitador da aprendizagem, compreensão e visualização do aluno (FERNANDES et al., 2006) e, em geral, estas orientações são implementadas pela maioria dos professores participantes.

Com os resultados apresentados, verifica-se a aceitação do computador pelos professores ao reconhecerem as suas potencialidades no ensino da disciplina, ao integrarem-no às suas práticas de ensino e ao constituírem novos recursos de ensino e aprendizagem disponíveis para os variados temas, tanto do ensino básico como do ensino secundário, indo ao encontro do estudo realizado por Amada e Carreira (2008).

Em geral, não podemos concluir acerca da real utilização do computador nas aulas de matemática de todas as escolas de Braga, como já foi mencionado, mas por meio da amostra analisada podem-se extrair algumas conclusões, com certo grau de confiabilidade, sobre as perspectivas dessa utilização. Alguns professores ainda não se aperceberam completamente o que o uso do computador pode significar para o ensino, enquanto que muitos acreditam e lutam para que essa utilização se torne algo mais frequente dentro das escolas, seja se baseando nos 
Programas Escolares ou em conhecimentos e concepções próprias. Em suma, o computador é utilizado nas aulas de matemática das escolas a que pertencem os professores inquiridos.

\section{REFERÊNCIAS}

AMADO, N.; CARREIRA, S. Utilização pedagógica do computador por professores estagiários de Matemática - diferenças na prática de sala de aula. In CANAVARRO, A. P.; MOREIRA, D.; ROCHA, M. I.(Orgs.), Tecnologias e educação matemática. Lisboa: Seção de Educação Matemática da Sociedade Portuguesa de Ciências da Educação, 2008. p. 286-299.

BLANCO, E.; SILVA, B. Tecnologia educativa em Portugal: conceito, origens, evolução, áreas de intervenção e investigação. Revista Portuguesa de Educação, v. 6, n. 3,p. 37-55. 1993.

COSTA, A. I. L.; CANAVARRO, A. P. Ensinar Matemática com computador: factores de inibição ou motivação das práticas dos professores. In CANAVARRO, A. P.; MOREIRA, D. ROCHA, M. I. (Orgs.). Tecnologias e Educação Matemática. Lisboa: Seção de Educação Matemática da Sociedade Portuguesa de Ciências da Educação, 2008. p. 300-312.

FERNANDES, J. A. et al. Tecnologias de informação e comunicação no currículo de matemática do ensino secundário após a reforma curricular de 1986. Revista de Estudos Curriculares, v. 4, n. 2, p. 291-329, 2006.

FERNANDES, J. A. Tecnologia gráfica no estudo de classes de funções. Educação e Matemática, v. 46, p. 33-36, 1998.

FERNANDES, J. A.; Vaz, O. Porquê usar tecnologias nas aulas de matemática? Boletim da SPM, $\mathrm{n}$. 39, p. 43-55, 1998.

GOLDENBERG, M. A Arte de Pesquisar: como fazer pesquisa qualitativa em Ciências Sociais. 7a ed. Rio de Janeiro: Record, 2013

HILL, M. M.; HILL, A. Investigação por questionário. Lisboa: Edições Sílabo, 2002.

LIMA, A. J. B. A utilização de tecnologias de informação e comunicação na aprendizagem da matemática por alunos brasileiros e portugueses do ensino médio/secundário. Dissertação (Mestrado em Ciências da Educação) - Instituto de Educação - Universidade do Minho, Portugal, 2011.

Ministério da Educação. Programa de Matemática A - 10 ano.2001a. Disponível em http://www.dgidc. min-edu.pt/ensinosecundario/index.php?s=directorio\&pid=2\&letra=M. Acesso em: jun. 2014.

Ministério da Educação. Programa de Matemática $B-10$ o ano. 2001b. Disponível em http://www.dgidc.min-edu.pt/ensinosecundario/index.php?s=directorio\&pid=2\&letra=M. Acesso em: jun. 2014.

Ministério da Educação. Programa de Matemática Aplicada às Ciências Sociais. 2001c. Disponível em http://www.dgidc.min-edu.pt/ensinosecundario/index.php?s=directorio\&pid=2\&letra=M. Acesso em: jun. 2014.

Ministério da Educação. Programa de Matemática $A-110$ ano. 2002a. Disponível em http://www.dgidc.min-edu.pt/ensinosecundario/index.php?s=directorio\&pid=2\&letra=M. Acesso em: jun. 2014. 
Ministério da Educação. Programa de Matemática $B-11$ ano. 2002b. Disponível em http://www.dgidc.min-edu.pt/ensinosecundario/index.php?s=directorio\&pid=2\&letra=M. Acesso em: jun. 2014.

Ministério da Educação. Programa de Matemática $A-12 \circ$ ano. 2002c. Disponível em http://www.dgidc. min-edu.pt/ensinosecundario/index.php?s=directorio\&pid=2\&letra=M. Acesso em: jun. 2014.

Ministério da Educação. Programa de Matemática $B-12$ ano. 2002d. Disponível em http://www.dgidc.min-edu.pt/ensinosecundario/index.php?s=directorio\&pid=2\&letra=M. Acesso em: jun. 2014.

Ministério da Educação. Modernização tecnológica do ensino em Portugal. Estudo de Diagnóstico. Lisboa: Gabinete de Estatística e Planeamento da Educação (GEPE), 2008.

Ministério da Educação. Programa de Matemática do Ensino Básico. 2007. Disponível em http://www.dgidc.min-edu.pt/ensinosecundario/index.php?s=dir-ectorio\&pid=2\&letra=M. Acesso em: ago. 2014.

NCTM. Curriculum and evaluation standards for school mathematics. Reston, NCTM, 1989.

NCTM. Principles and standards for school mathematics. Reston, NCTM, 2000.

PONTE, J. P.; CANAVARRO, A. P. Matemática e novas tecnologias. Lisboa: Universidade Aberta, 1997.

VALENTE, J. A. (Org,). Computadores e conhecimento: repensando a educação.Campinas: Gráfica Central da UNICAMP, 1993.

VISEU, S. A utilização das TIC nas escolas portuguesas: alguns indicadores e tendências. In COSTA, F. A.; PERALTA, H.; VISEU, S.(Org.), As TIC na educação em Portugal: Concepções e práticas. Porto: Porto Editora, 2007. p. 37-59.

VISEU, F., LIMA, A. J. B.; FERNANDES, J. A. Um estudo comparativo sobre o uso das TIC na aprendizagem de matemática do ensino secundário/médio em Portugal e no Brasil. Educação Matemática e Pesquisa, v. 15, n 2, p. 293-316, 2013. 